\title{
China's syphilis epidemic: epidemiology, proximate determinants of spread, and control responses
}

\author{
Joseph D. Tuckera,b,c and Myron S. Cohen ${ }^{a}$ \\ aDivision of Infectious Disease, UNC Chapel Hill School of Medicine, Chapel Hill, North Carolina, \\ USA \\ ' Infectious Diseases Unit, Massachusetts General Hospital, Boston, Massachusetts, USA \\ 'STD Control Department, Guangdong Provincial Center for STI \& Skin Diseases Control, \\ Guangzhou, China
}

\begin{abstract}
Purpose of review-China has experienced an increase in the incidence and prevalence of syphilis that is especially remarkable since this infection was virtually eradicated in the country 50 years ago. The purpose of this analysis is to provide an overview of recent literature on syphilis proximate determinants and potential public health responses.
\end{abstract}

Recent findings-Per capita syphilis burden is greatest in coastal urban China. There are a number of biological, demographic, geographic, and behavioral/social proximate determinants of syphilis spread that distinguish the Chinese syphilis epidemic. These determinants portend the need for intensified syphilis control efforts, including: comprehensive testing and treatment; integration with HIV, sexually transmitted infection, and antenatal services; scale-up of novel rapid syphilis test technology, and multisectorial support.

Summary-The Chinese central government recently announced a 10-year syphilis plan to provide clear expectations for evaluating the success of local syphilis control programs and integration with HIV testing programs. Further research is needed to understand the social and behavioral determinants driving the spread of syphilis.

\section{Keywords}

China; MSM; sex worker; social; syphilis

\section{Introduction}

China implemented massive syphilis control programs during the 1950s, including empiric penicillin treatment of high-risk groups and large-scale structural interventions intended to destabilize the commercial sex industry [1]. These public health measures were largely effective in curbing the spread of syphilis and other sexually transmitted infections (STIs) for several decades. However, during the past 20 years syphilis has made a resurgence [2]. By way of comparison, there were more syphilis cases in the province of Guangdong in 2008 than reported in the entire European Union during the same year [3]. Responding to these trends, the Chinese Ministry of Health recently announced a 10-year plan for syphilis control and prevention, recognizing the reemergence of syphilis as an important public

(C) 2011 Wolters Kluwer Health | Lippincott Williams \& Wilkins

Correspondence to Dr Joseph D. Tucker, Infectious Diseases Unit, GRJ-504, Massachusetts General Hospital, Boston, MA 02139, USA Tel: +1 617726 6000; fax: +1 617726 7653; jtucker4@ partners.org. 
health threat and renewing interest in syphilis control programs [4]. Many regions in China have a remarkably high incidence of syphilis [2], providing an opportunity to better understand the spread of syphilis and how it can be controlled. Although individual risk factors for syphilis infection have been well described (unprotected sex, etc.), the more proximate determinants of syphilis spread are less understood. There are several potential explanations for China's increasing syphilis burden, and better understanding the determinants of syphilis may help inform control programs and beyond. This study describes syphilis epidemiology, proximate determinants of syphilis spread, and promising public health responses in the Chinese context.

\section{Syphilis epidemiology}

Accurately estimating the incidence of syphilis is complicated by imperfect traditional serological assays that accompany frequently incomplete clinical histories. A positive treponemal test alongside a nontreponemal test with a titer of $1: 32$ could represent an incident case, prior treated infection, or a serofast result. The Chinese case definition of syphilis requires positive treponemal and nontreponemal tests and consistent clinical and physical findings [5]. Reported syphilis case data in China are augmented by cross-sectional studies, cohorts, surveillance data, and case reports in the Chinese literature.

Syphilis cases per 100000 population in China have been consistently greater in coastal urban parts of China (Fig. 1). This tendency for cases to cluster in urban regions may be related to greater numbers of rural-to-urban migrants with higher sexual risk in those areas, but also could be a function of greater diagnostic capacity in the urban regions. Although there were administrative changes in syphilis case reporting in 2003-2004, both case report data [2] and cross-sectional data [6] suggest an expanding Chinese syphilis epidemic during the past 8 years (Fig. 2). A number of studies have found higher syphilis prevalence among men who have sex with men (MSM) $\left[7^{\bullet}, 8,9,10^{*}, 11,12,13^{\circ}, 14\right]$, STI clinic patients [15 $]$, and female sex workers $\left[16,17^{\circ}\right]$. Studies of syphilis among low-risk groups such as pregnant women have found a considerable burden of disease as well $[6,18,19]$. For example, one study of nearly half a million pregnant women in Shenzhen found that $0.5 \%$ had syphilis [20]. These data highlight the reemergence of syphilis in China.

\section{Potential determinants of syphilis in China}

There are several potential determinants of the spread of syphilis in China: rural-to-urban migration, increased young unmarried men, limited routine screening, incomplete partner notification, stigma associated with health-seeking among high-risk groups, and perhaps lack of partial immunity.

Rural-to-urban migration on an enormous scale in China may expand localized syphilis outbreaks. The rural-to-urban migrant population exceeds 100 million individuals, and several small studies have suggested that these migrants have higher risk of sexual behavior than their rural counterparts [21,22]. There have been very few studies of syphilis outside of urban China [23], reflecting fewer STI clinics and limited treponemal diagnostics in China's rural regions. Understanding the complexity of rural-to-urban migration and how it attenuates or exacerbates sexual risk behaviors is important.

Demographic changes underway have transformed the composition and size of traditional high-risk groups, widening inroads for the expansion of syphilis [24]. Since the 1980s China has had a skewed sex ratio that demographers estimate has already caused a surplus of over 30 million unmarried men [25]. This group of largely poor, uneducated men will be underemployed, promoting rural-to-urban migration. Modeling studies $\left[26,27^{\circ}\right]$ and qualitative research [28] suggest that these `surplus men' may have increased sexual risk, 
expanding demand for commercial sex. Another demographic change may have important implications for syphilis spread. MSM in China have a very high syphilis incidence $\left[7^{\circ}, 8,9\right]$, and because cultural practices promote marriage of MSM, there is considerable additional risk for heterosexual syphilis transmission.

There have been substantive changes in the routine syphilis screening that could affect syphilis spread. In 2003-2004 the Chinese compulsory premarital health check that included syphilis testing was phased out, decreasing the pool of young, screened women. As most couples in China only have children after marriage, this routine screening likely prevented a large number of adverse outcomes related to syphilis infection among pregnant women. While antenatal syphilis screening has accelerated in several regions, none of these programs has reached the scale or uniformity of the previous premarital screening program.

Stigma related to seeking sexual health services discourages routine screening and may decrease the willingness of high-risk individuals to promptly seek sexual health services in some settings. Qualitative [29] and quantitative [30,31] studies of health-seeking behaviors among those with genitourinary symptoms reveal that many individuals do not seek care in the official standardized clinic system. Small studies of female sex workers $\left[32^{\circ}, 33\right]$ and rural-to-urban migrants $\left[34^{\circ}\right]$ have shown that although many high-risk groups are interested in HIV and STI testing, uptake at designated clinic sites has been low.

Biological differences in syphilis transmission efficacy may exist. A study analyzing reported primary and secondary syphilis cases in the United States during a 50-year period found evidence of endogenous oscillation [35] which might be explained by partial immunity. During the 1960s and 1970s, STIs, including syphilis, were extremely rare [1]. This extraordinarily low prevalence of syphilis may have limited herd immunity, priming the Chinese population for a dramatic resurgence in disease burden. More data on syphilis transmission efficiency are needed to understand if immunological factors play a role.

\section{Responses to China's syphilis epidemic}

The large burden of syphilis in China demands more epidemiological investigation, increased screening, integration of syphilis/HIV programs, expanded partner services, more effective behavioral interventions, and multisectorial commitment. In terms of epidemiology, there have been discrepant reports regarding the burden of congenital syphilis in many regions of the country. Data from antenatal surveillance sites revealed only a modest increase in syphilis prevalence in pregnant women [36] although the number of congenital syphilis cases has continued to increase [37]. Lack of standard diagnostics and misdiagnosis of congenital syphilis [38 $\left[8^{\circ}\right.$ on the one hand and under-reporting of cases [30] on the other emphasizes the need for further epidemiological work.

Expanding syphilis screening programs is an essential response to China's syphilis epidemic. Screening for pregnant women as part of a premarital examination must be considered and there have been promising pilot programs [20]. Expanding prenatal screening has the advantage of preventing both maternal and congenital syphilis cases, leveraging the extensive maternal child health infrastructure available in many urban regions wherein syphilis is more prevalent [20].

New rapid syphilis tests that rely on immunochromato-graphic technology will allow expanded syphilis testing. Rapid treponemal tests are fast, accurate, inexpensive, and do not require trained personnel or refrigeration [39]. Rapid syphilis testing may increase the yield of clinic-based screening programs because of shorter patient wait times, ease of use in the laboratory, and low cost. Since these tests can use pinprick blood specimens, this also represents an opportunity to augment routine clinic-based syphilis testing in sex venues and 
other nontraditional testing sites. A paper comparing local rapid syphilis test results to national reference laboratory results showed excellent specificity and sensitivity [40].

China has made great strides in HIV control and prevention [41], and the strong biological and social connection between syphilis and HIV further support integration of syphilis/HIV programs. There are two complementary ways of integrating syphilis and HIV testing, and prevention, and control efforts: expanding free syphilis testing at HIV voluntary counseling and testing sites and/or expanding free HIV testing at clinics wherein individuals are tested for syphilis (STI clinics, etc). Although the first approach has met resistance due to low baseline HIV voluntary counseling and testing (VCT) uptake, the second approach has been successful in several Southern Chinese cities $\left[15^{\circ}, 30\right]$. Our recent study of over 2000 STI clinic patients in six cities found that over $80 \%$ of patients accepted integrated syphilis/HIV testing $\left[15^{\circ}\right]$.

Establishing systems of partner notification and partner services may also be important for syphilis control in China. Robust systems for partner notification are incomplete in many regions [42]. Partner notification in China is typically limited to providing case patients with a partner referral card, but comprehensive public health procedures for partner notification, testing, and follow-up do not exist. The lack of an effective partner service system in China likely increases reinfection rates among discordant couples, an especially thorny issue in the context of stigma associated with syphilis. Cost-effectiveness studies and further successful programmatic pilots in China may help to convince policymakers and local public health officials of the importance of partner notification programs.

Targeted behavioral interventions for syphilis prevention and control are also needed. Limited peer-based behavioral intervention pilots have been implemented among MSM in China $[12,43,44]$, but more rigorous and larger studies are needed in this field. Especially in light of the high digital connectivity among Chinese MSM, online [45] or mobile phone based syphilis prevention interventions [46] should be considered. Unfortunately the literature on behavioral interventions among high-risk heterosexual individuals is similarly sparse.

The final and perhaps most essential part of syphilis control is multilevel commitment from public health, STI, maternal health, and medical agencies. The recent announcement of a 10year syphilis control plan from the Ministry of Health in China (Table 1) gives special priority to such efforts and indicates high-level government support for expanding syphilis control efforts. This 10-year plan includes specific benchmarks for evaluating the success of the control program, focusing on integration of HIV/syphilis testing and control programs. Local syphilis control programs supported by WHO pilots, local governments, and other agencies are underway in a number of provinces now.

\section{Conclusion}

Rapid social changes across the past several decades in China have allowed for the expansion of a substantial syphilis epidemic. Although some of the proximate determinants of syphilis will be difficult to offset in the short-term (unbalanced sex ratios and surplus men, potential immunological differences), there are several discrete and changeable determinants of the syphilis epidemic. Expanding syphilis screening as part of clinic-based and community-based efforts will help ensure that infectious individuals are quickly diagnosed, treated, and counseled. Integration of syphilis testing into other critical public health and medical infrastructures, notably the HIV testing and care system, represents a feasible and scalable intervention to thwart China's syphilis epidemic. Although creating partner notification systems may take time, starting pilot programs and conducting 
feasibility studies are critical early steps for these proven public health tools to make an impact in the future. Cost-effectiveness studies [47] and further policy work will help justify the expanded resources necessary to undertake these steps. The Chinese Ministry of Health's bold new syphilis control plan reveals where China hopes to be in 2015 and 2020 with respect to syphilis. Now is the time to leverage local and regional syphilis resources in China to successfully realize these benchmarks.

\section{Key points}

- After near eradication 50 years ago, syphilis has made a resurgence in China.

- According to the national case reporting system, syphilis burden is greatest along coastal urban regions in China.

- There are a number of proximate determinants of the Chinese syphilis epidemic that are related to geographic, demographic, behavioral, screening and social changes.

- A comprehensive syphilis control program should leverage these social forces and integrate syphilis programs into the already widespread systems for sexually transmitted infection clinical care, HIV care, and antenatal care.

- The Chinese Ministry of Health recently announced a major 10-year plan for syphilis prevention and control that has clear benchmarks, establishing a strong foundation to reinforce syphilis control in China.

\section{Acknowledgments}

The authors would like to thank Brian Vicini for administrative help and Professor Xiang-Sheng Chen (National Center for STD Control, Chinese Academy of Medical Sciences and Peking Union Medical College Institute of Dermatology, Nanjing, China) for comments on an earlier draft of this manuscript. We acknowledge a National Institutes of Health (NIH) Fogarty K01 Award (US NIH 1K01TW008200-01A1), the University of North Carolina (UNC) Fogarty AIDS International Research and Training Program (NIH FIC D43 TW01039), the UNC Social Science Research on HIV/AIDS in China (NIH NICHD R24 HD056670-01), the UNC Center for AIDS Research, and the Harvard Institute for Global Health.

Funding for the study was received from the US NIH 1K01TW008200-01A1, University of North Carolina Center for AIDS Research, and NIH NICHD R24 HD056670-01.

\section{References and recommended reading}

Papers of particular interest, published within the annual period of review, have been highlighted as:

- of special interest

•• of outstanding interest

Additional references related to this topic can also be found in the Current World Literature section in this issue (pp. 87-88).

1. Cohen MS, Henderson GE, Aiello P, Zheng H. Successful eradication of sexually transmitted diseases in the People's Republic of China: implications for the 21st century. J Infect Dis. 1996; 174(Suppl 2):S223-S229. [PubMed: 8843252]

2. Chen ZQ, Zhang GC, Gong XD, et al. Syphilis in China: results of a national surveillance programme. Lancet. 2007; 369:132-138. [PubMed: 17223476]

3. Yang, LG. Annual STD surveillance for Guangdong province, China. China National STI Control Conference; Haikou. 2010. 
4. Xinhua News. AIDS-level prevention measures to slow soaring syphilis. Jun 21st. 2010 Available online at: http://news.xinhuanet.com/english2010/china/2010-06/21/c_13361528.htm

5. Sexually transmitted infections: operational standards and laboratory testing methods. Chinese National Centers for Disease Control and Prevention, National STD Control Center; Nanjing: 2006.

6. Lin CC, Gao X, Chen XS, et al. China's syphilis epidemic: a systematic review of seroprevalence studies. Sex Transm Dis. 2006; 33:726-736. [PubMed: 16755273]

7•. Ruan Y, Jia Y, Zhang X, et al. Incidence of HIV-1, syphilis, hepatitis B, and hepatitis C virus infections and predictors associated with retention in a 12-month follow-up study among men who have sex with men in Beijing, China. J Acquir Immune Defic Syndr. 2009; 52:604-610. [PubMed: 19710617]

8. Yang H, Hao C, Huan X, et al. HIV incidence and associated factors in a cohort of men who have sex with men in Nanjing, China. Sex Transm Dis. 2010 Epub ahead of print.

9. Xu JJ, Zhang M, Brown K, et al. Syphilis and HIV seroconversion among a 12-month prospective cohort of men who have sex with men in Shenyang, China. Sex Transm Dis. 2010; 37:432-439. [PubMed: 20375928]

10••. Wong FY, Huang ZJ, Wang W, et al. STIs and HIV among men having sex with men in China: a ticking time bomb? AIDS Educ Prev. 2009; 21:430-446. [PubMed: 19842827]

11. Xiao Y, Sun J, Li C, et al. Prevalence and correlates of HIV and syphilis infections among men who have sex with men in seven provinces in China with historically low HIV prevalence. J Acquir Immune Defic Syndr. 2010; 53(Suppl 1):S66-S73. [PubMed: 20104113]

12. Muessig KE, Tucker JD, Wang BX, Chen XS. HIV and syphilis among men who have sex with men in China: the time to act is now. Sex Transm Dis. 2010 Epub ahead of print.

13•. Wei C, Guadamuz TE, Stall R, Wong FY. STD prevalence, risky sexual behaviors, and sex with women in a national sample of Chinese men who have sex with men. Am J Public Health. 2009; 99:1978-1981. [PubMed: 19762670]

14. Li Y, Detels R, Lin P, et al. Prevalence of HIV and STIs and associated risk factors among female sex workers in Guangdong Province, China. J Acquir Immune Defic Syndr. 2010; 53(Suppl 1):S48-S53. [PubMed: 20104110]

15•. Yang, LG.; Tucker, JD.; Yang, B. Twin response to twin epidemics: integrated HIV/syphilis testing at STI clinics in south China. Late breaker oral presentation FRLBE106. XVIII International AIDS Conference; July 23rd 2010; Vienna: International AIDS Society; 2010.

16. Wang L, Ding ZW, Ding GW, et al. Data analysis of national HIV comprehensive surveillance sites among female sex workers from 2004 to 2008. Zhonghua Yu Fang Yi Xue Za Zhi. 2009; 43:1009-1015. [PubMed: 20137527]

17•. Wang Q, Yang P, Gong XD, et al. Syphilis prevalence and high risk behaviors among female sex workers in different settings. Chin J AIDS STDs. 2009; 15:398-400.

18. Zhu L, Qin M, Du L, et al. Maternal and congenital syphilis in Shanghai, China, 2002 to 2006. Int J Infect Dis. 2010; 3:e45-e48. [PubMed: 20137991]

19. Shen YL, Xu YP, Wu LM. Epidemiological analysis of congenital syphilis from year 1998 to 2007 in Zhejiang province. Zhonghua Liu Xing Bing Xue Za Zhi. 2009; 30:96-97. [PubMed: 19565860]

20. Cheng JQ, Zhou H, Hong FC, et al. Syphilis screening and intervention in 500000 pregnant women in Shenzhen, the People's Republic of China. Sex Transm Infect. 2007; 83:347-350. [PubMed: 17693449]

21. Li X, Fang X, Lin D, et al. HIV/STD risk behaviors and perceptions among rural-to-urban migrants in China. AIDS Educ Prev. 2004; 16:538-556. [PubMed: 15585430]

22. He N, Cao H, Yin Y, et al. Herpes simplex virus-2 infection in male rural migrants in Shanghai, China. Int J STD AIDS. 2009; 20:112-114. [PubMed: 19182057]

23. Hong Y, Li X, Yang H, et al. HIV/AIDS-related sexual risks and migratory status among female sex workers in a rural Chinese county. AIDS Care. 2009; 21:212-220. [PubMed: 19229691]

24. Tucker, JD.; Poston, D.; Qiang, R. Gender policy and HIV in China: catalyzing policy change. 1st ed.. Springer; New York: 2009. 
25. Zhu WX, Lu L, Hesketh T. China's excess males, sex selective abortion, and one child policy: analysis of data from 2005 national intercensus survey. BMJ. 2009; 338:b1211. [PubMed: 19359290]

26. Pan Y, Wu J. Population profiling in China by gender and age: implication for HIV incidences. BMC Public Health. 2009; 9(Suppl 1):S9. [PubMed: 19922693]

27•. Ebenstein, A.; Jennings, E. 'Bare branches', prostitution, and HIV in China: a demographic analysis. In: Tucker, JD.; Poston, DL.; Ren, Q., editors. Gender policy and HIV in China: catalyzing policy change. Springer; New York: 2009.

28. Pan, S.; Huang, YY.; Liu, ZY.; Wang, J. Report on male clients in China: HIV risks and preventions [in Chinese]. Universal Press; GaoXiong: 2008.

29. Lieber E, Chin D, Li L, et al. Sociocultural contexts and communication about sex in China: informing HIV/STD prevention programs. AIDS Educ Prev. 2009; 21:415-429. [PubMed: 19842826]

30. Tucker JD, Yang LG, Zhu ZJ, et al. Integrated syphilis/HIV screening in China: a qualitative analysis. BMC Health Serv Res. 2010; 10:58. [PubMed: 20205942]

31. Guan J, Wu Z, Li L, et al. Self-reported sexually transmitted disease symptoms and treatmentseeking behaviors in China. AIDS Patient Care STDS. 2009; 23:443-448. [PubMed: 19519228]

32. Wang Y, Li B, Zheng J, et al. Factors related to female sex workers' willingness to utilize VCT service: a qualitative study in Jinan city, northern China. AIDS Behav. 2009; 13:866-872. [PubMed: 18770027]

33. Wang Y, Li B, Pan J, et al. Factors associated with utilization of a free HIV VCT clinic by female sex workers in Jinan city, northern China. AIDS Behav. 2010 Epub ahead of print.

34•. He N, Zhang J, Yao J, et al. Knowledge, attitudes, and practices of voluntary HIV counseling and testing among rural migrants in Shanghai, China. AIDS Educ Prev. 2009; 21:570-581. [PubMed: 20030500]

35. Grassly NC, Fraser C, Garnett GP. Host immunity and synchronized epidemics of syphilis across the United States. Nature. 2005; 433:417-421. [PubMed: 15674292]

36. Wu Z, Zhou PY. Letter to editor. N Engl J Med. 2010; 363:1088-1089. [PubMed: 20825326]

37. Tucker JD, Chen XS, Peeling RW. Syphilis and social upheaval in China. N Engl J Med. 2010; 362:1658-1661. [PubMed: 20445179]

38• Wu DD, Hong FC, Feng TJ, et al. Congenital syphilis: refining newborn evaluation and management in Shenzhen, southern China. Sex Transm Infect. 2010; 86:280-284. [PubMed: 20576913]

39. Tucker JD, Bu J, Brown LB, et al. Accelerating worldwide syphilis screening through rapid testing: a systematic review. Lancet Infect Dis. 2010; 10:381-386. [PubMed: 20510278]

40. Yin YP, Wei WH, Wang HC, et al. Performance of serological tests for syphilis in sexually transmitted diseases clinics in Guangxi Autonomous Region, China: implications for syphilis surveillance and control. Sex Health. 2009; 6:5-9. [PubMed: 19254485]

41. Wu Z, Sun X, Sullivan SG, Detels R. Public health. HIV testing in China. Science. 2006; 312:1475-1476. [PubMed: 16763133]

42. Alam N, Chamot E, Vermund SH, et al. Partner notification for sexually transmitted infections in developing countries: a systematic review. BMC Public Health. 2010; 10:19. [PubMed: 20082718]

43. Zhang HB, Zhu JL, Wu ZY, et al. Intervention trial on HIV/AIDS among men who have sex with men based on venues and peer network. Zhonghua Yu Fang Yi Xue Za Zhi. 2009; 43:970-976. [PubMed: 20137518]

44. Zeng G, Xiao Y, Xu P, et al. Evaluation of effect of community-based HIV/AIDS interventions among men who have sex with men in eighteen cities, China. Zhonghua Yu Fang Yi Xue Za Zhi. 2009; 43:977-980. [PubMed: 20137519]

45. Zou H, Wu Z, Yu J, et al. Sexual risk behaviors and HIV infection among men who have sex with men who use the internet in Beijing and Urumqi, China. J Acquir Immune Defic Syndr. 2010; 53(Suppl 1):S81-S87. [PubMed: 20104115]

46. Swendeman D, Rotheram-Borus MJ. Innovation in sexually transmitted disease and HIV prevention: internet and mobile phone delivery vehicles for global diffusion. Curr Opin Psychiatry. 2010; 23:139-144. [PubMed: 20087189] 
47. Hong FC, Liu JB, Feng TJ, et al. Congenital syphilis: an economic evaluation of a prevention program in China. Sex Transm Dis. 2010; 37:26-31. [PubMed: 19734825] 


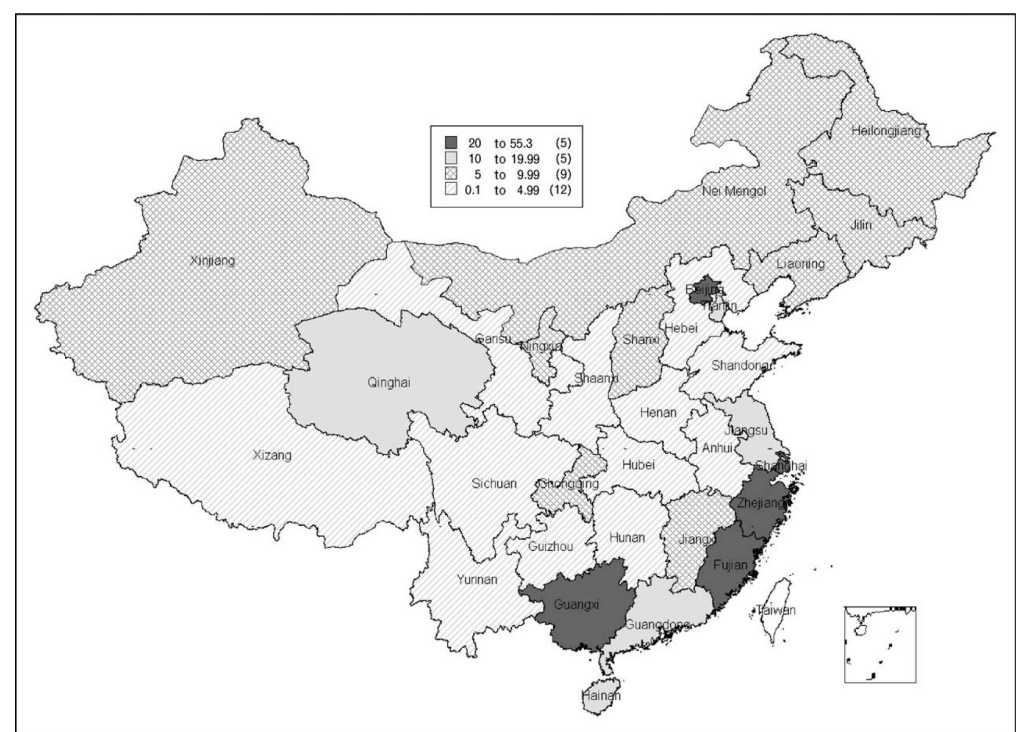

Figure 1. Reported syphilis cases per 100000 population at the level of the province or provincelevel metropolis

Reproduced with permission from [2]. 


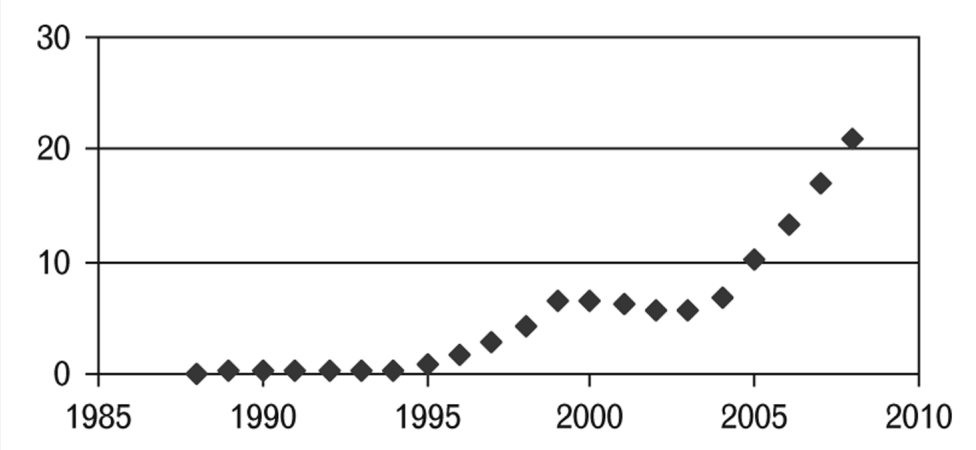

Figure 2. Reported total syphilis cases per 100000 population Reproduced with permission from [37]. 
Table 1

Chinese Ministry of Health 2010-2020 syphilis control plan

\begin{tabular}{|c|c|c|}
\hline Variable & 2015 benchmark & 2020 benchmark \\
\hline $\begin{array}{l}\text { Primary and secondary } \\
\text { syphilis cases }\end{array}$ & $\begin{array}{l}\text { Less than } 5 \% \text { increase in new primary and secondary } \\
\text { syphilis cases }\end{array}$ & Decreasing new primary and secondary syphilis \\
\hline $\begin{array}{l}\text { Incident congenital syphilis } \\
\text { cases }\end{array}$ & $\begin{array}{l}\text { Less than } 30 \text { congenital syphilis cases per } 100000 \\
\text { live births }\end{array}$ & $\begin{array}{l}\text { Less than } 15 \text { congenital syphilis cases per } 100000 \\
\text { live births }\end{array}$ \\
\hline \multirow{2}{*}{$\begin{array}{l}\text { Syphilis prevention and } \\
\text { treatment knowledge (among } \\
15-49 \text {-year-old population) }\end{array}$} & $\begin{array}{l}\text { Urban residents }-85 \% \\
\text { Rural residents }-75 \%\end{array}$ & $\begin{array}{l}\text { Urban residents }-90 \% \\
\text { Rural residents }-80 \%\end{array}$ \\
\hline & $\begin{array}{l}\text { Floating population }^{a}-80 \% \\
\text { Unlicensed prostitutes }^{b}-90 \% \\
\text { MSM }-90 \%\end{array}$ & $\begin{array}{l}\text { Floating population }^{a}-85 \% \\
\text { Unlicensed prostitutes }^{b}-95 \% \\
\text { MSM }-90 \%\end{array}$ \\
\hline $\begin{array}{l}\text { Health professional's mastery } \\
\text { of knowledge and technical } \\
\text { skills }\end{array}$ & $\begin{array}{l}\text { Syphilis control and prevention in general }-85 \% \\
\text { Maternal to child syphilis control }-80 \%\end{array}$ & $\begin{array}{l}\text { Syphilis control and prevention in general }-100 \% \\
\text { Maternal to child syphilis control }-90 \%\end{array}$ \\
\hline $\begin{array}{l}\text { Voluntary syphilis test } \\
\text { physician offer rates and } \\
\text { patient treatment acceptance } \\
\text { rates }\end{array}$ & $\begin{array}{l}\text { STI clinics }-80 \% \text { offer and } 80 \% \text { accept treatment } \\
\text { HIV VCT sites - } 90 \% \text { offer and } 90 \% \text { accept } \\
\text { treatment } \\
\text { Drug rehabilitation centers }-90 \% \text { offer and } 90 \% \\
\text { accept treatment }\end{array}$ & $\begin{array}{l}\text { STI clinics }-90 \% \text { offer and } 90 \% \text { accept treatment } \\
\text { HIV VCT sites }-95 \% \text { offer and } 95 \% \text { accept } \\
\text { treatment } \\
\text { Drug rehabilitation centers }-95 \% \text { offer and } 95 \% \\
\text { accept treatment }\end{array}$ \\
\hline $\begin{array}{l}\text { Pregnant woman test } \\
\text { coverage, mother treatment } \\
\text { acceptance, child entry into } \\
\text { care }\end{array}$ & $\begin{array}{l}\text { Urban }-80 \% \text { test coverage, } 90 \% \text { accept treatment, } \\
90 \% \text { children in care } \\
\text { Rural }-60 \% \text { test coverage, } 70 \% \text { accept treatment, } \\
80 \% \text { children in care }\end{array}$ & $\begin{array}{l}\text { Urban }-90 \% \text { test coverage, } 95 \% \text { accept treatment, } \\
95 \% \text { children in care } \\
\text { Rural }-70 \% \text { test coverage, } 80 \% \text { accept treatment, } \\
85 \% \text { children in care }\end{array}$ \\
\hline $\begin{array}{l}\text { Surveillance and laboratory } \\
\text { quality control system }\end{array}$ & $\begin{array}{l}\text { Establish an online monitoring system and laboratory } \\
\text { quality control system }\end{array}$ & $\begin{array}{l}\text { Continued improvements in surveillance and } \\
\text { monitoring, including syphilis evaluation in HIV } \\
\text { evaluation }\end{array}$ \\
\hline
\end{tabular}

Source: Sohu News. Ministry of Health issued Planning, Prevention and Control of syphilis in China (2010-2020) June 22, 2010. Available online at http://stock.sohu.com/20100621/n272945797.shtml.

Floating population (liudong renkou) is a commonly used term used to describe rural-to-urban migrants in China.

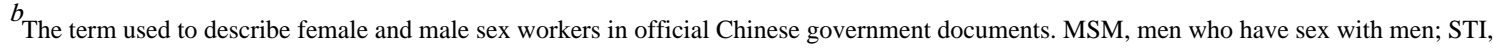
sexually transmitted infection; VCT, voluntary counseling and test. 